\title{
Remote sensing of the urban heat island effect across biomes in the continental USA
}

\author{
Marc L. Imhoff ${ }^{\mathrm{a}, *}$, Ping Zhang a,b, Robert E. Wolfe ${ }^{\mathrm{a}}$, Lahouari Bounoua ${ }^{\mathrm{a}}$ \\ a Hydrospheric and Biospheric Science Laboratory, NASA's Goddard Space Flight Center, Greenbelt, MD, 20771, USA \\ b Earth Resource Technology Inc., Annapolis Junction, MD, 20701, USA
}

\section{A R T I C L E I N F O}

\section{Article history:}

Received 4 August 2009

Received in revised form 6 October 2009

Accepted 9 October 2009

\section{Keywords:}

Urban heat island

Remote sensing

MODIS

Land surface temperature

Biomes

Landsat

Impervious surface area

\begin{abstract}
A B S T R A C T
Impervious surface area (ISA) from the Landsat TM-based NLCD 2001 dataset and land surface temperature (LST) from MODIS averaged over three annual cycles (2003-2005) are used in a spatial analysis to assess the urban heat island (UHI) skin temperature amplitude and its relationship to development intensity, size, and ecological setting for 38 of the most populous cities in the continental United States. Development intensity zones based on \%ISA are defined for each urban area emanating outward from the urban core to the nonurban rural areas nearby and used to stratify sampling for land surface temperatures and NDVI. Sampling is further constrained by biome and elevation to insure objective intercomparisons between zones and between cities in different biomes permitting the definition of hierarchically ordered zones that are consistent across urban areas in different ecological setting and across scales.

We find that ecological context significantly influences the amplitude of summer daytime UHI (urban-rural temperature difference) the largest $\left(8^{\circ} \mathrm{C}\right.$ average) observed for cities built in biomes dominated by temperate broadleaf and mixed forest. For all cities combined, ISA is the primary driver for increase in temperature explaining $70 \%$ of the total variance in LST. On a yearly average, urban areas are substantially warmer than the non-urban fringe by $2.9^{\circ} \mathrm{C}$, except for urban areas in biomes with arid and semiarid climates. The average amplitude of the UHI is remarkably asymmetric with a $4.3^{\circ} \mathrm{C}$ temperature difference in summer and only $1.3^{\circ} \mathrm{C}$ in winter. In desert environments, the LST's response to ISA presents an uncharacteristic "U-shaped" horizontal gradient decreasing from the urban core to the outskirts of the city and then increasing again in the suburban to the rural zones. UHI's calculated for these cities point to a possible heat sink effect. These observational results show that the urban heat island amplitude both increases with city size and is seasonally asymmetric for a large number of cities across most biomes. The implications are that for urban areas developed within forested ecosystems the summertime UHI can be quite high relative to the wintertime UHI suggesting that the residential energy consumption required for summer cooling is likely to increase with urban growth within those biomes.
\end{abstract}

Published by Elsevier Inc.

\section{Introduction}

In 2008 more than half of the world's population were urban dwellers and the urban population is expected to reach $81 \%$ by 2030 (UNFPA, 2007). As the process of global urbanization accelerates both in intensity and area there is growing interest in understanding its implications with respect to a broad set of environmental factors including net primary production (Imhoff et al., 2000), biodiversity (Reid, 1998; Ricketts \& Imhoff, 2003; Sisk et al., 1994 and others), and climate and weather at local, regional, and global scales (Trenberth et al., 2007).

Urban heating and the formation of the urban heat island (UHI) is one attribute of urban land transformation that is of interest across science

\footnotetext{
* Corresponding author. Biospheric Sciences Branch Code 614.4, NASA's Goddard Space Flight Center, Greenbelt, MD, 20771, USA. Tel.: +1 301614 6628; fax: +1 301 6146695.

E-mail address: Marc.L.Imhoff@nasa.gov (M.L. Imhoff).
}

disciplines because the UHI signal reflects a broad suite of important land surface changes impacting human health, ecosystem function, local weather and possibly climate. The UHI phenomenon is generally seen as being caused by a reduction in latent heat flux and an increase in sensible heat in urban areas as vegetated and evaporating soil surfaces are replaced by relatively impervious low albedo paving and building materials. This creates a difference in temperature between urban and surrounding non-urban areas. This temperature differential was first referred to as the Urban Heat Island by Manley (1958) and since then a large effort has been devoted to the study of this important urban phenomenon using both air temperature and surface temperature (e.g. Grimmond \& Oke, 2002; Quattrochi \& Ridd, 1994; Shepherd \& Burian, 2003; Rosenzweig et al., 2005).

Many observational studies estimated the magnitude of UHI by comparing ground based observed air temperature in urban and rural weather stations (e.g., Oke, 1973). In general the air temperature defined UHI has a strong diurnal cycle and is more important at night. The potential impact of UHI's on long term air temperature trend 
analyses is well known and a considerable effort has been made to correct air temperature biases when comparing UHI effects across different regions (e.g., Gallo et al., 1993; Hansen et al., 2001; Karl et al., 1988; Kukla et al., 1986).

The urban heat phenomenon can also be characterized by surface temperatures. While surface temperatures can be both higher and more variable than concurrent air temperatures due to the complexity of the surface types in urban environments and variations in urban topography (e.g. Nichol, 1996; Streutker, 2002), they are more easily related to surface conditions themselves (Nichol \& Wong, 2005; Owen et al., 1998; Voogt \& Oke, 2003). Since surfaces heat and cool more rapidly than air, the greatest surface temperatures are observed during midday versus nighttime for air temperature (Roth et al., 1989).

Our interest is in the surface UHI effect because the conversion of surfaces more directly links to the alteration of a broader suite of physical and biophysical processes related to the intensity and trajectory of land cover change. Moreover, we are interested both in how the UHI varies as a function of the intensity of urban land conversion as well as ecological context.

Remotely-sensed data of land surface temperature, vegetation index, and other surface characteristics have been widely used to describe UHI phenomenon (Gallo \& Owen, 1999; Gallo et al., 1993; Weng et al., 2004) but comparisons across different urban areas have been hampered by the lack of objectively quantifiable and commonly agreed upon definitions for urban density, and urban versus non-urban area. The development of impervious surface area (ISA) data derived from $30 \mathrm{~m}$ Landsat ETM + and IKONOS imagery (Yang et al., 2002; Homer et al., 2004) is a reasonable solution providing a continental-wide map of impervious surface fractional areas. The ISA data estimate the relative amount of impenetrable surface area, such as pavements for roads and parking lots and roofing materials which in aggregate have been identified as a key environmental indicator of urban land use and water quality (Arnold \& Gibbons, 1996). The ISA data have been used successfully in combination with other comparable resolution remotely sensed data of land surface temperature and vegetation indices to characterize temperature differences (Xian \& Crane, 2005; Yuan \& Bauer, 2007).

While these detailed studies provide an excellent basis for understanding the fine scale processes, the broader consequences of ecological context are often overlooked. The strength of urban land transformation as a driver or forcing of change depends upon its ecological context (i.e., the type of land surface that is being altered relative to the broader landscape functional groupings), the degree to which the previous physical and biophysical systems are altered, and the extent and distribution of the altered surfaces. While in general the amplitude of the urban heat island has been positively correlated with urban density, it is a relative measure (urban - rural temperature). This means that the ecological context has consequences on both intensity and sign through its influence on the thermal characteristics of the rural area. A weak urban heat island or urban heat sink phenomenon, for example, has been observed in semi-arid and arid climates (where the rural areas are desert shrubland) despite high urban densities (Bounoua et al., 2009; Brazel et al., 2000; Lougeay et al., 1996; Pena, 2008; Shepherd, 2006).

Furthermore, as a driving process at the landscape level, the nonrandom placement of urban infrastructure also has an effect. Altering relatively small but naturally resource rich areas can have a larger impact on certain processes than larger alterations on functionally less important ones. Much of this of course depends on the process of interest. Imhoff et al. (2000), Imhoff et al. (1997) and Nizeyaimana et al. (2001) for example showed that because urbanization in the U.S. has taken place on the most naturally productive soils it has had a disproportionately large impact on continental scale potential Net Primary Production (NPP). Urbanizing less than $3 \%$ of the land surface, for example, was enough to offset the gains in NPP made by the conversion of $29 \%$ of the land surface to agriculture because the urban land conversion took place on the best soils. A similar case has been made for assessing urbanization risk to biodiversity (Reid, 1998; Ricketts \& Imhoff, 2003; Sisk et al., 1994).

In this paper we use a combination of satellite and ecological map data to characterize and inter-compare the UHI response across biomes in the continental U.S. We examine the relationship between \% ISA and land surface temperature across many cities, calculate seasonal UHI for cities in similar ecological settings, and compare the amplitude of the UHI for the major biomes.

\section{Methods and data}

\subsection{Terrestrial ecoregions}

One of our primary objectives is to study the influence of ecological context on UHI amplitude for varying urban densities. Since the degree to which urbanization alters ecosystem function or state is relative to what was there before, the ecological setting within which the process occurs establishes the baseline conditions for quantifying change. To allow comparisons of urban places within and between settings we use the terrestrial ecoregions map developed by Olson et al. (2001) to stratify the analyses and constrain the sampling around each urban area according to its biome. The ecoregions map divides the continental United States into 10 biomes each representing an assemblage of biophysical, climate, botanical, and animal habitat characteristics defining a distinct geographical area. We chose to stratify sampling of U.S. cities using this perspective because climate factors are contained in them as well as other biogeographical information needed to understand the dynamic arena within which ecological processes and anthropogenic influences such as urbanization most strongly interact.

Table 1

The top 38 most populated urban areas in the continental U.S. used in this study grouped by biome.

\begin{tabular}{|c|c|}
\hline Biome & Cities \\
\hline \multicolumn{2}{|l|}{ FE } \\
\hline $\begin{array}{l}\text { Temperate broadleaf and mixed } \\
\text { forest (northern group) }\end{array}$ & $\begin{array}{l}\text { Baltimore MD, Boston MA Cleveland OH, } \\
\text { Columbus OH, Washington DC, Detroit MI, } \\
\text { Milwaukee WI, Minneapolis MN, New York NY, } \\
\text { Philadelphia PA Pittsburgh PA }\end{array}$ \\
\hline \multicolumn{2}{|l|}{$F A$} \\
\hline $\begin{array}{l}\text { Temperate broadleaf and mixed } \\
\text { forest (southern group) }\end{array}$ & Atlanta GA, Charlotte NC, Memphis TN \\
\hline \multicolumn{2}{|l|}{ GN } \\
\hline $\begin{array}{l}\text { Temperate grasslands, savannahs } \\
\text { and shrublands }\end{array}$ & $\begin{array}{l}\text { Chicago IL, Oklahoma City OK, Omaha NE, } \\
\text { Saint Louis MO, Tulsa OK, Wichita KA, } \\
\text { Kansas City, KS }\end{array}$ \\
\hline \multicolumn{2}{|r|}{ 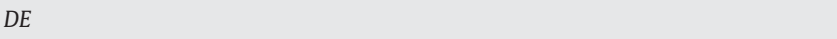 } \\
\hline Desert and xeric shrublands & $\begin{array}{l}\text { Albuquerque NM, El Paso TX, Las Vegas NV, } \\
\text { Phoenix AZ, Tucson AZ }\end{array}$ \\
\hline \multicolumn{2}{|l|}{ MS } \\
\hline $\begin{array}{l}\text { Mediterranean forests, } \\
\text { woodlands, shrub }\end{array}$ & $\begin{array}{l}\text { Fresno CA, Los Angeles CA ,Sacramento CA, } \\
\text { San Diego CA, San Jose CA }\end{array}$ \\
\hline \multicolumn{2}{|l|}{ GS } \\
\hline $\begin{array}{l}\text { Temperate grasslands, savannahs } \\
\text { and shrublands }\end{array}$ & Austin TX, Dallas TX, San Antonio, TX \\
\hline \multicolumn{2}{|l|}{ GT } \\
\hline $\begin{array}{l}\text { Tropical and subtropical } \\
\text { grasslands, savannahs } \\
\text { and shrublands }\end{array}$ & Houston TX, New Orleans LA \\
\hline \multicolumn{2}{|l|}{ FW } \\
\hline Temperate coniferous forest & Portland OR, Seattle WA \\
\hline
\end{tabular}

We sub-divided Temperate Broadleaf and Mixed Forests into a northern group (FE) and a southern group (FA) otherwise all other biomes are as rendered by the Olson ecoregions map (Olson et al., 2001). 
In this study we analyze data for 38 of the most populated urban areas in the continental United States occurring across six of the largest biomes. We further subdivide two of the larger biomes in the set (Temperate Broadleaf and Mixed Forest and Temperate Grasslands, Savannas and Shrublands) differentiating Northeast and MidAtlantic forest and Northern versus Southern Mid-western grasslands (Table 1). In this study, all temperature and NDVI data collected for an individual urban area is included in the analysis only if they remain in the dominant biome. This eliminates cross-over into different bioclimatic environments as a potential contaminant of the observed temperature differences within an urban area and allows grouping and comparison of UHI effects by biome.

\subsection{Classification of urban density}

We use the impervious surface area (ISA) data from the Landsatderived, continental scale land cover map (NLCD) in a Geographic Information System-based spatial analysis to identify individual urban areas, stratify them internally according to ISA density, and estimate their size. The fractional area impervious surface data were derived using Landsat 7 ETM+ and IKONOS differentiating man-made surfaces from natural or vegetated surfaces (see Yang et al., 2002). While this parameter does not contain retrievable information about albedo or 3D structure, it captures development intensity as a function of the extent and spatial distribution of the collection of man-made surfaces within a pixel. Conversion intensity based on ISA can be related to changes in the biophysics of the land surface including sensible and latent heat fluxes within the urban surface and boundary layers through comparison with other spatially co-registered data. Most recently, Yuan and Bauer (2007) and Xian \& Crane (2005) demonstrated that ISA data developed from ETM+ and the NLCD could be used to make rigorous comparisons of urban density and surface temperature at local scales suggesting broader application would be possible with appropriate temperature data.

We use a 25\% ISA threshold to define polygons in the Landsat-based thematic data. The 25\% threshold identifies a reasonable boundary between urban and low intensity residential lands (Lu \& Weng, 2006) and provides reasonably spatially coherent urban groupings (Fig. 1). As such the polygons we define here overlap named cities but do not necessarily match incorporated or cadastral (administrative) boundaries. Most important; however, is the close match between the area defined by the $25 \%$ ISA threshold and the MODIS landcover map classifying Urban Built-Up land (Fig. 1d). MODIS LST retrieval algorithms rely on this map for estimating surface emissivity (Wan et al., 2004) so a close match here ensures that temperature comparisons within the urban polygon are based on retrievals using the same parameter sets.

Once individual city place urban polygons are defined we further stratify the landscape within and around them using classes based on ISA and distance. In this paper we define five zones based on classes of \% ISA in concentric rings emanating outward from the highest ISA in a city to the lowest: 1) Urban Core= pixels having $75 \%$ to $100 \%$ ISA (these are the highest in a city polygon); 2) Urban1= pixels having ISA between $75 \%$ and $50 \%(75 \%>$ ISA $\geq 50 \%)$; 3 ) Urban $2=$ pixels
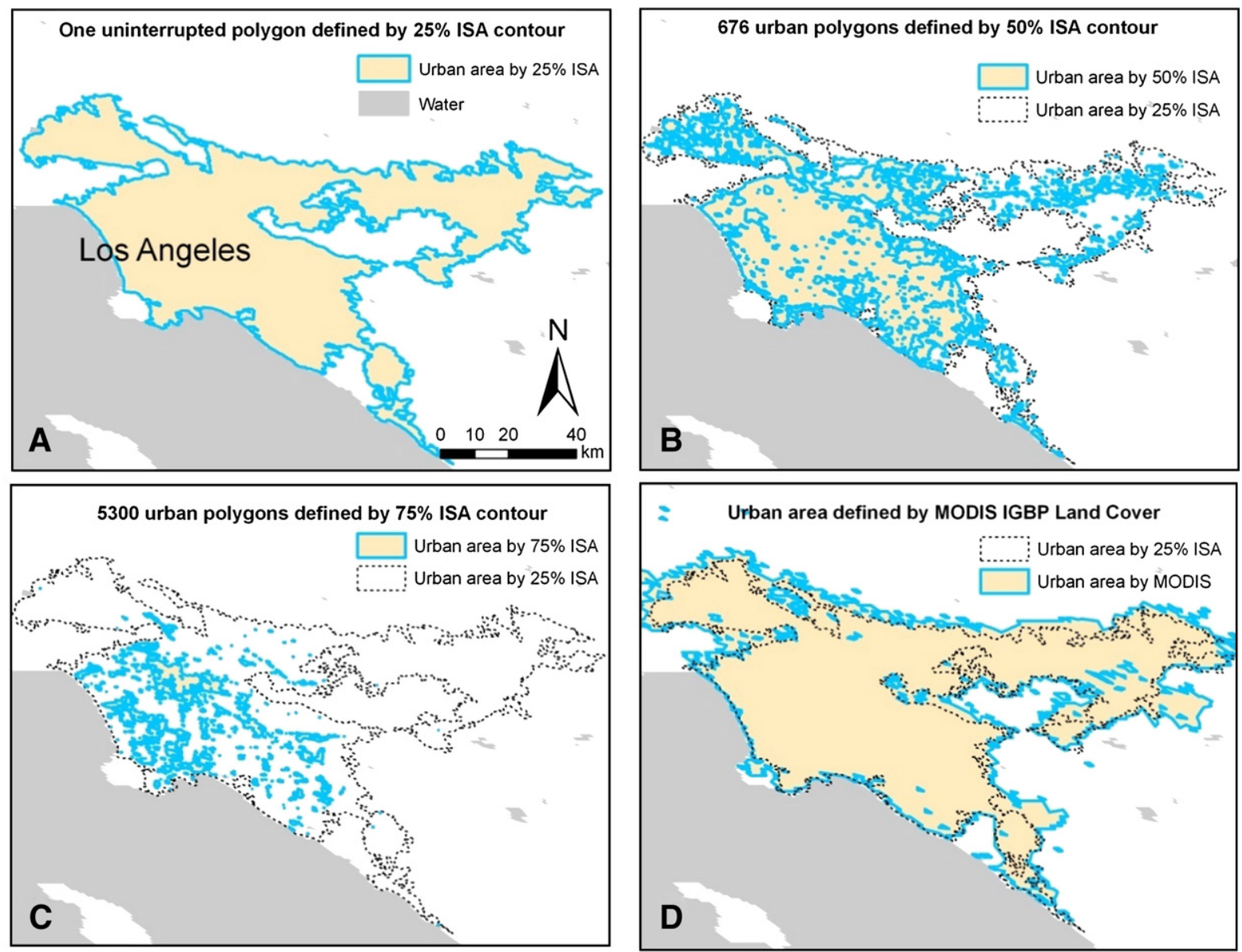

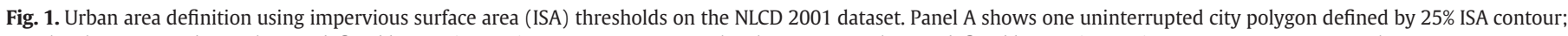

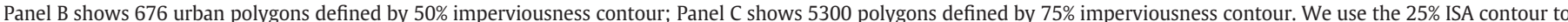

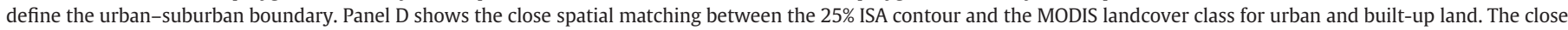

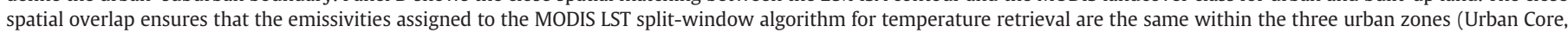
Urban1, and Urban2). 
having between $50 \%$ and $25 \%$ ISA ( $50 \%>$ ISA $\geq 25 \%$ ) - this is the last urban zone and its outer boundary identifies the 25\% threshold; 4) Suburban $=$ pixels located in a buffer zone $0-5 \mathrm{~km}$ adjacent to and outside the 25\% ISA contour (pixels have less than 25\% ISA); and 5) Rural ( or non-urban) $=$ pixels located in a $5 \mathrm{~km}$ wide ring located between 45 and $50 \mathrm{~km}$ away from the 25\% ISA contour and having less than 5\% ISA (Fig. 2a,b). This rural ring is chosen to be at an optimal distance far enough from the urban core to represent a remote rural area yet not too far to infringe into the $25 \%$ contour of an adjacent urban area or another biome. Pixels that fall into overlapping biomes, other urban areas or topographic elevations $\pm 50 \mathrm{~m}$ off the mean elevation of the urban core are excluded from the analysis.

\subsection{Land surface temperature (LST) and NDVI}

To characterize the surface temperature and the presence of vegetation within the ISA zones, we use MODIS-Aqua Version 5, 8-day composite (MOD11A2) LST with high quality control (Wan et al., 2004) and 16-day composite NDVI (Huete et al., 1994, 1997) at $1 \mathrm{~km} \times 1 \mathrm{~km}$ resolution (both covering 2003 to 2005). LST's from MOD11A2 are retrieved from clear-sky (99\% confidence) observations at 1:30 PM and 1:30 AM using a generalized split-window algorithm (Wan \& Dozier, 1996). The coefficients used in the split window algorithm are given by interpolating a set of multi-dimensional look- up tables (LUT) derived by linear regression of MODIS simulation data from radiative transfer calculations over wide ranges of surface and atmospheric conditions. These look up tables have been continuously upgraded (Wan et al., 2004) and comparisons between MODIS LST's and in-situ measurements across a wide set of test sites indicate the accuracy is better than $1 \mathrm{~K}$ with an RMS (of differences) less than $0.5 \mathrm{~K}$ in most cases (Wan, 2008; Wang et al., 2008).

The LST data are used to characterize the horizontal temperature gradient across the urban area and NDVI is used to describe the vegetation density temporal variation for each urban zone. As mentioned previously, temperature and NDVI data for each zone in an urban area are only collected if they remain in the dominant biome for that city. This eliminates cross-over into different bio-climatic environments as a potential contaminant of the observed temperature differences within an urban area and allows grouping and comparison of UHI effects by biome.

\subsection{Topographic and population data}

Topographic data are used as a filter to exclude from the analysis temperature differences due to elevation and shading. We use the 925 m SRTM30 (Farr \& Kobrick, 2000) dataset to determine a mean elevation of the urban area and exclude from analysis all pixels whose elevation is outside the $+/-50 \mathrm{~m}$ window from the mean elevation.

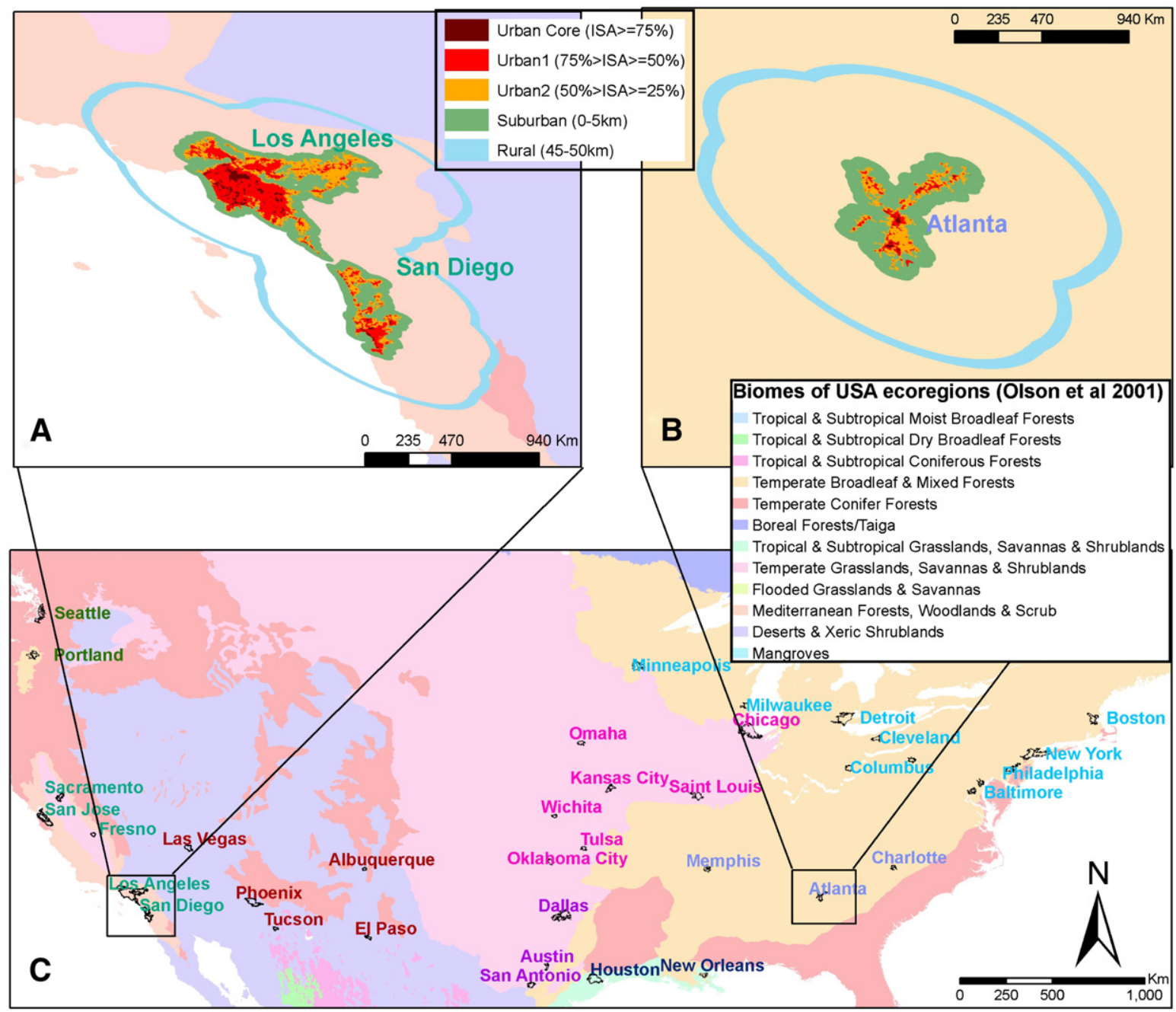

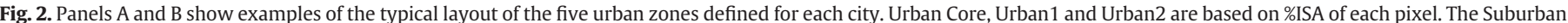

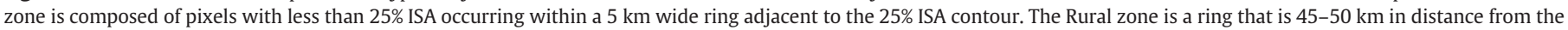

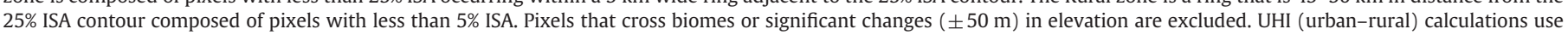
MODIS LST averages from the Urban Core and Rural zones. Panel C shows the cities used in this analysis and their biomes according to Olson et al. (2001). 
We also use the $30 \mathrm{arc}$ sec $(\sim 925 \mathrm{~m})$ US Census Grids 2000 (Deichmann et al., 2001) produced by the Center for International Earth Science Information Network to characterize the population.

\section{Results and discussion}

\subsection{The UHI and ecological context}

Using the population data, we identified 38 of the most populated urban areas in the continental United States distributed over eight different biomes (Table 1, Fig. 2c). For each urban area, a spatial stratification defining the five ISA zones is applied. A 0.1 NDVI threshold is used to exclude water, bare soil and other non-vegetated pixels from the spatial and temporal average in the rural zone of each urban area.

For all cities across the biomes, the impervious surface area decreases from the urban core with about $80 \%$ average ISA to the rural area where all pixels have less than 5\% ISA. Also, the average impervious surface fraction within the five zones identified in each city is remarkably similar indicating that the ISA zonal classification is sufficiently consistent for inter-comparison (Fig. 3a). The average summer daytime MODIS land surface temperature (1:30 PM local time averaged for June, July and August) for all cities and zones show that temperatures increase with ISA in all cases except urban areas in desert and xeric shrubland ecoregions (DE) (Fig. 3b). Despite the difference in spatial resolution, the MODIS $1 \mathrm{~km}$ NDVI tracks the ISA data remarkably well showing an increase outward from the urban core in all biomes except DE which shows a convex pattern (Fig. 3c). The anomalous NDVI and LST patterns for desert and xeric shrubland cities is likely a result of increased vegetation and latent heat flux in less dense $50-25 \%$ urban and suburban fringe areas due to resource (water) augmentation in those areas. This pattern has been noted previously for U.S. desert cities using AVHRR (Imhoff et al., 2004) and Landsat (Xian \& Crane; 2005).

In terms of the UHI, we calculated the average temperature differences (Urban Core LST - Rural LST) for all the cities in each biome for summer (June/July/August) and winter (December/January/February) daytime (1:30 PM) and nighttime (1:30 AM). The UHI responses for the eight different biomes were all significantly different $(p=0.01)$ and clearly show the effect of ecological context on seasonal and diurnal UHI amplitudes (Fig. 4). As expected, with surface temperatures the greatest temperature differences are noted in daytime (Roth et al., 1989). On average we found that the summer UHI was significantly larger than the winter UHI. Energy demand in metropolitan areas is determined by a complex variety of factors related to the nature of the demand, the spatial distribution of high demand centers and numerous other factors. However, our results suggest that for residential areas potential increases in cooling requirements in summer would more than offset gains realized by heating in winter. The amplitude of summer daytime UHI appears to
A

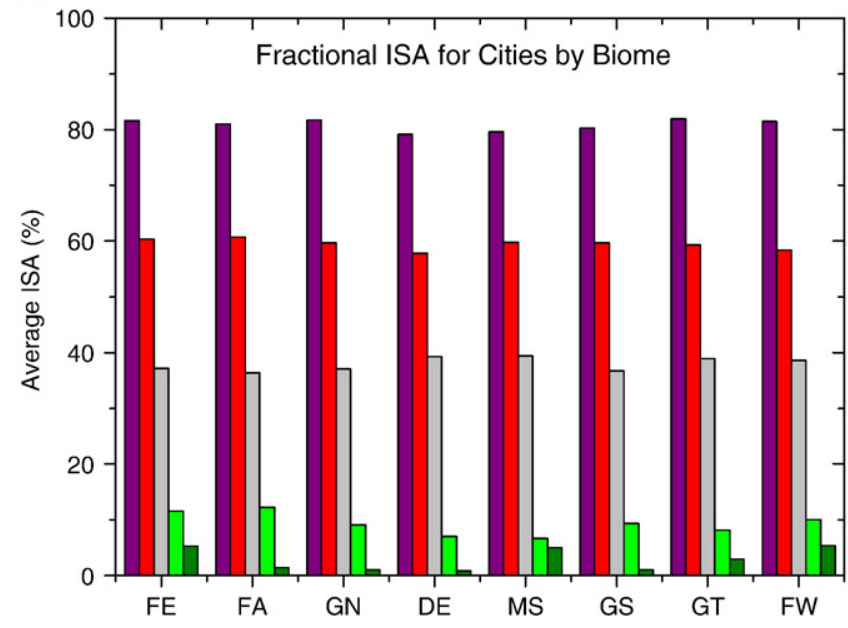

C

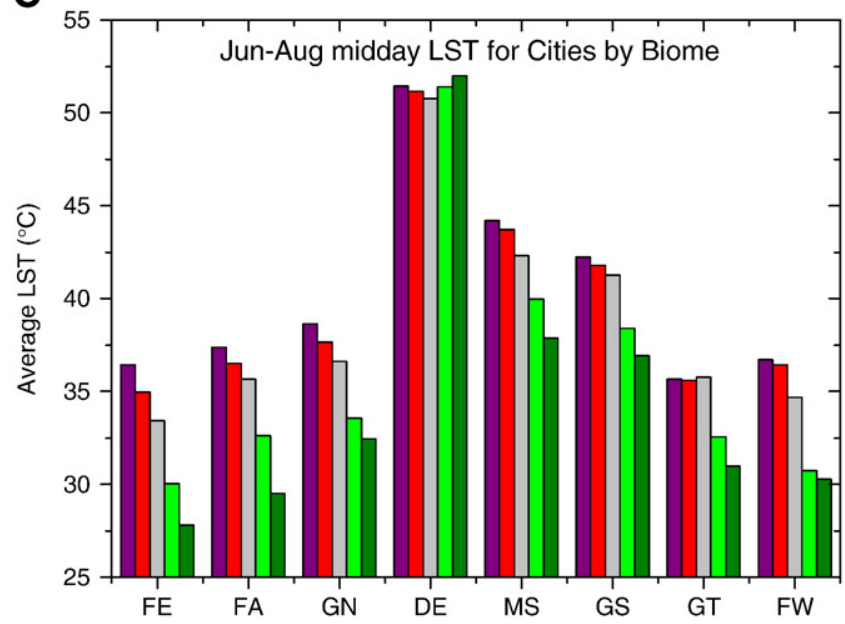

B

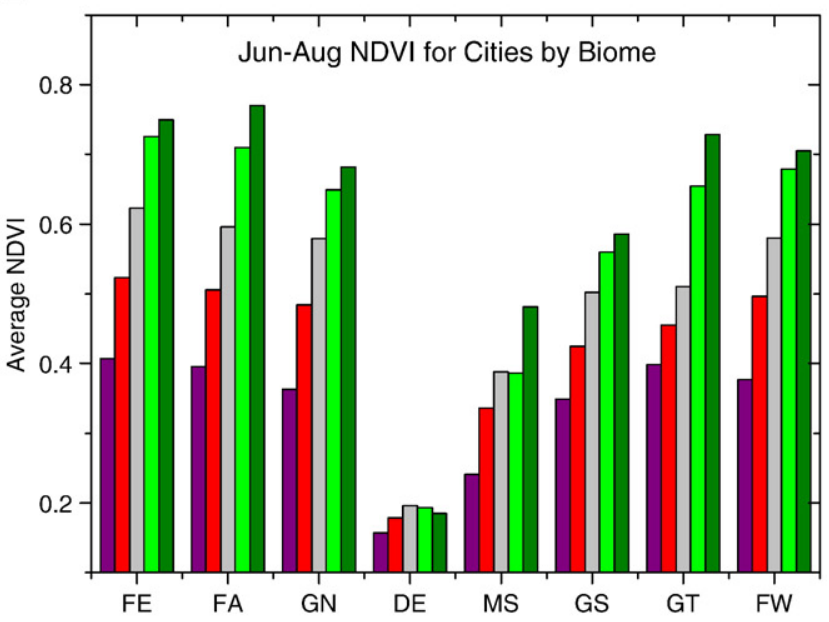

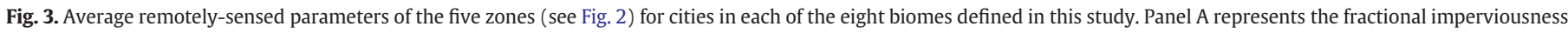

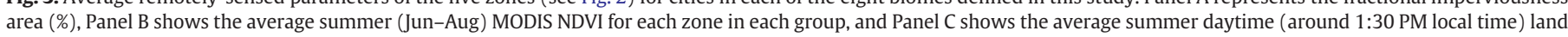
surface temperature derived from MODIS product. 


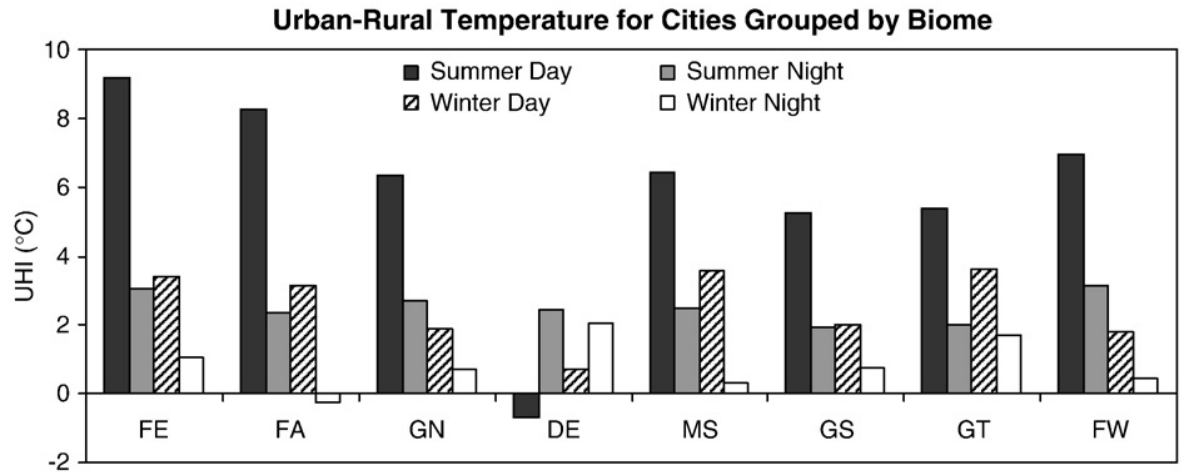

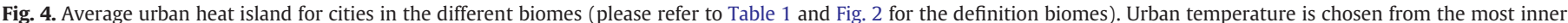

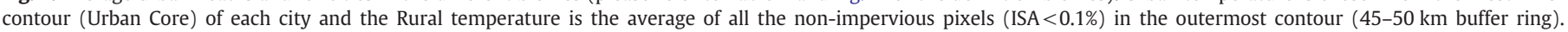

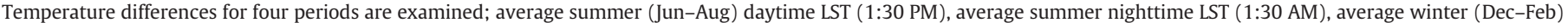
daytime, and average winter nighttime LST.

be related to the standing biomass of the surrounding biome decreasing from forests to grasslands and reversing to a heat sink in desert cities. The largest average summer daytime UHI $\left(7\right.$ to $\left.9{ }^{\circ} \mathrm{C}\right)$ for example is noted for cities displacing temperate broadleaf, mixed, and temperate coniferous forest biomes (FE, FA, and FW). In high biomass forested biomes, urban areas are surrounded by dense and tall vegetation which intercepts and re-evaporates precipitation at potential rates and diffuses water from the deep soil to the atmosphere during the process of photosynthesis, thus keeping the surrounding regions much cooler than the less vegetated urban core. In contrast, urban areas dominated by shorter low biomass vegetation such as grassland, shrublands and savannah (groups GN, MS, GS and GT) produce a less intense UHI with amplitudes ranging from 4 to $6{ }^{\circ} \mathrm{C}$. In these regions, the zones surrounding the Urban Core are
A

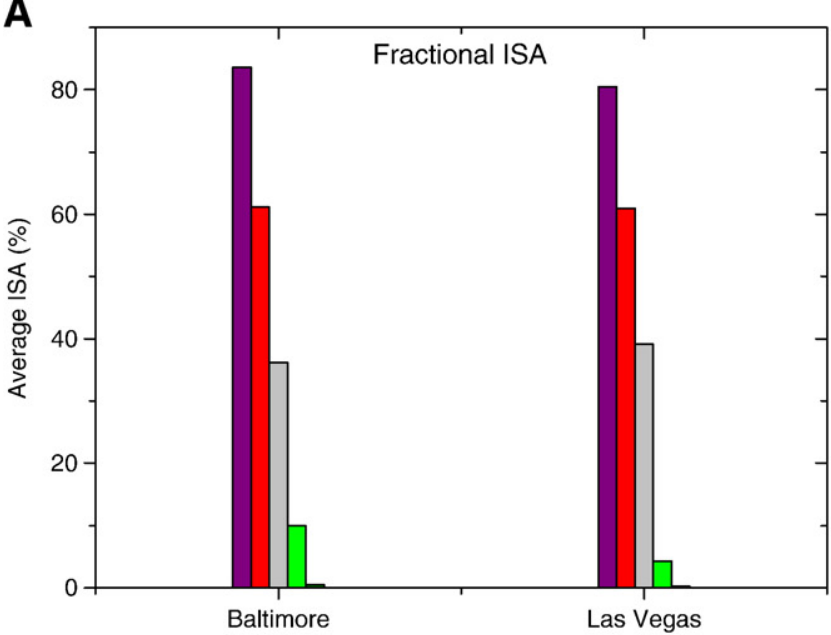

C

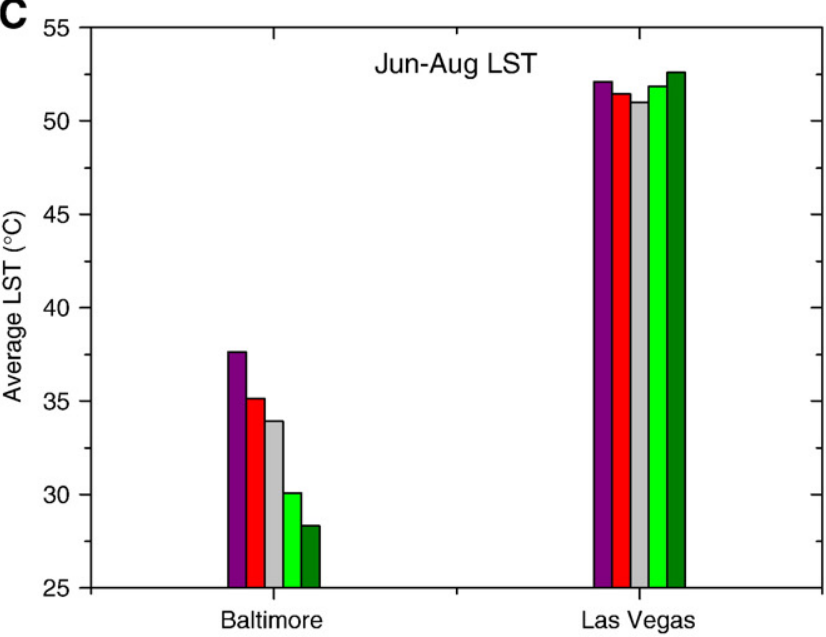

B

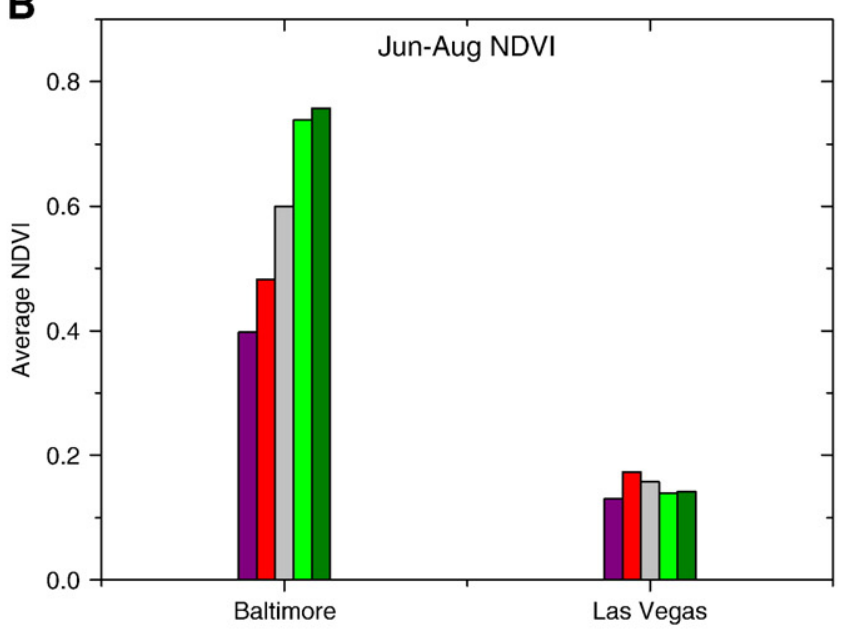

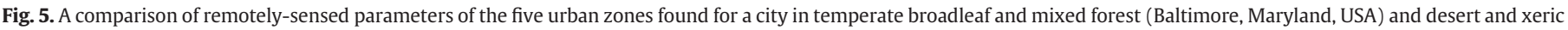

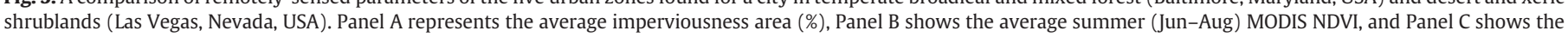
average summer daytime MODIS LST for each zone. 
sparsely vegetated and restore an important part of the absorbed solar energy as sensible heating; thus reducing the horizontal temperature gradient between the Urban Core and the Rural Zone. In urban areas surrounded by deserts and xeric shrublands (DE) this temperature contrast weakens and even reverses. The summer daytime UHI data for DE was actually slightly negative $\left(-1^{\circ} \mathrm{C}\right)$ and taken in isolation it would tend to corroborate the heat sink effect noted for many desert cities. However, the summer nighttime and winter daytime and nighttime UHI's for DE are still positive and large enough to make the cities warmer overall than the outlying areas. Urban areas in the DE biome were also the only ones to consistently show a larger nighttime UHI effect. To further examine the influence of ecological context we compare average summer daytime LST across ISA zones for Baltimore, Maryland, located in the Northeastern Temperate Broadleaf and Mixed Forest (group FE) and Las Vegas, Nevada, an urban area built within the Desert and Xeric Shrubland biome and arid climate conditions (Fig. 5).

The two urban areas are similar with respect to the average fractional ISA found in each of the defined urban zones (Fig. 5a); however, the density of the vegetation surrounding them, as illustrated by the NDVI (Fig. 5b) is sharply different. The NDVI difference between the Rural Zone and the Urban Core is 0.4 in Baltimore and less than 0.1 for Las Vegas. In Las Vegas; however, the vegetation density increases (initially) away from the Urban Core (e.g., Urban1, Urban2 and Suburban) then drops again in the Rural Zone. This suggests that the less dense urban zones (Urban2 and Suburban) in Las Vegas are supporting plant growth (e.g., exotic tree and shrub species and lawns through irrigation) at a rate greater than that of the surrounding biome (Imhoff et al., 2004). These two cities demonstrate the importance of ecological context as a modulator of the UHI effect. While the urban core in Baltimore creates a well-defined UHI with amplitude of $9.3^{\circ} \mathrm{C}$, in Las Vegas, it points to a possible heat sink (about $0.5{ }^{\circ} \mathrm{C}-$ a small number relative to the accuracy of the MODIS LST product). If only the Urban2 zone (50-25\% ISA) in Las Vegas is compared to its rural zone, there is a temperature increase of $1.6^{\circ} \mathrm{C}$. These results at least trend in the direction of a potential heat sink effect for arid cities postulated by some (e.g. Bounoua et al., 2009; Shepherd, 2005, 2006). Composite averaged summer day LST profiles across the Urban Core for the two urban areas are illustrated in Fig. 6.

\subsection{Quantifying the relationship between LST and ISA}

We quantify the relationships between the fractional area of impervious surfaces and the UHI by analyzing the LST and ISA anomalies for all 38 urban areas. The close spatial overlap of the MODIS landcover (urban built-up) with the three urban zones we define in this study (Urban Core, Urban1 and Urban2) ensures that the emissivities assigned to the MODIS LST split-window algorithm for temperature retrieval are mostly the same (Fig. 2d). Even though the differences in the emissivities are small this further reduces the possibility of LUT induced signal in the comparison of LST's between ISA zones (Wan, 2008).

For each urban polygon we compute the mean summer daytime LST anomaly of each zone by subtracting from its LST the average obtained over all five zones. As expected, changes in ISA fraction strongly affect changes in LST. For all of the urban areas combined, changes in ISA control about 70\% of the variance in LST. In general, at a 0.001 significance level, about $60-90 \%$ of the variance in LST is explained by changes in ISA and these results are well in line with similar comparisons of ISA and LST for the Twin Cities Metroplex in Minnesota (Yuan \& Bauer, 2007). With the exception of DE, in general there is positive relationship between LST and ISA. We found the ISA/ LST relationship to be strongest for urban areas in forested biomes (e.g., group FE, FA and FW) where variations in ISA explain more than $85 \%$ of the variation in LST (Table 2, Fig. 7a). We also note that the rate of change in LST as a function of ISA is different for urban areas in

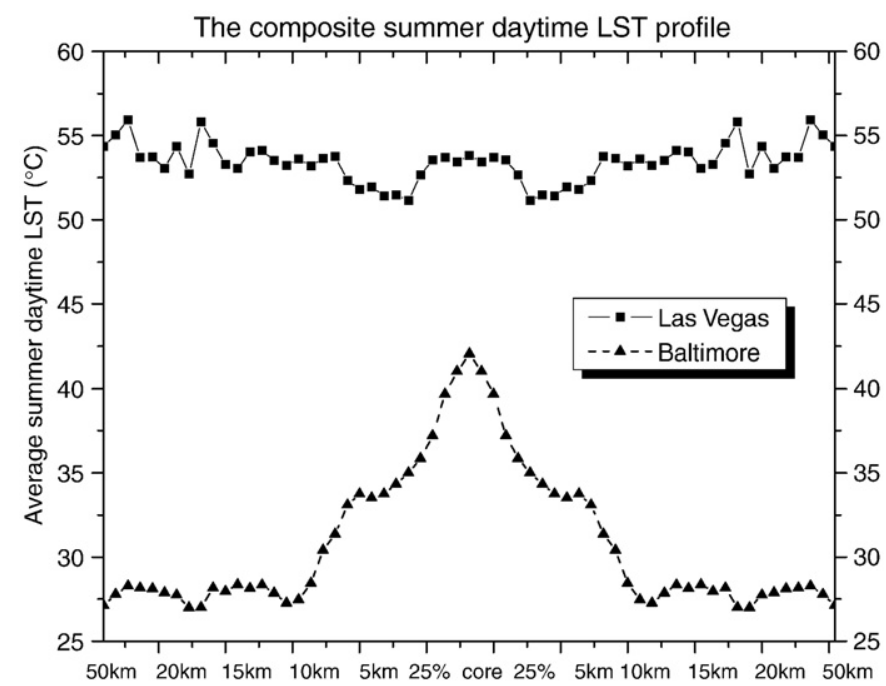

Fig. 6. Composite averaged summer (Jun-Aug) daytime LST profile from MODIS across all urban zones. Baltimore (black triangles) located in temperate forests and Las Vegas (black squares) in a desert. Averages are computed from 12 cross-sections obtained at $15^{\circ}$ interval and for $180^{\circ}$ around the urban area. The entire profile is finally obtained using symmetry with respect to the urban center.

forested biomes forests versus those characterized by short vegetation. For example, at $95 \%$ confidence limit, the slope of the linear fit is $10 \%$ for temperate forested groups FE, FA, and FW while it is only $6 \%$ for shorter vegetations (e.g., group GN, MS, GS, and GT). This implies that the rate of temperature increase with ISA is influenced by ecological context (i.e., regional climate, surrounding vegetation, soils) as well as its impervious surface fractional area driven evaporation capacity. One possible explanation for this is that short vegetation surrounding urban areas in the southern and central parts of the country will experience heat stress more quickly than forest vegetation. This would cause a more frequent reduction of the transpiration rates in those biomes thereby increasing the surface

Table 2

The linear parameters relating average summer (Jun-Aug) daytime (1:30 PM) MODIS LST anomaly (dependent) and impervious surface area anomaly (independent) for the 38 top population cities in the continental U.S. grouped by the biomes in which they reside.

\begin{tabular}{|c|c|c|c|}
\hline \multirow[t]{2}{*}{ Biomes } & \multicolumn{3}{|c|}{ Linear fit } \\
\hline & $\overline{R^{2}}$ & Slope (with 95\% confidence interval) & $P$-value \\
\hline All combined & 0.70 & $\begin{array}{l}0.073 \\
0.066-0.080\end{array}$ & $<0.0001$ \\
\hline FE & 0.92 & $\begin{array}{l}0.107 \\
0.098-0.115\end{array}$ & $<0.0001$ \\
\hline FA & 0.86 & $\begin{array}{l}0.092 \\
0.069-0.114\end{array}$ & $<0.0001$ \\
\hline GN & 0.89 & $\begin{array}{l}0.077 \\
0.067-0.086\end{array}$ & $<0.0001$ \\
\hline $\mathrm{DE}$ & a & a & a \\
\hline MS & 0.80 & $\begin{array}{l}0.078 \\
0.061-0.095\end{array}$ & $<0.0001$ \\
\hline GS & 0.86 & $\begin{array}{l}0.066 \\
0.050-0.081\end{array}$ & $<0.0001$ \\
\hline GT & 0.73 & $\begin{array}{l}0.058 \\
0.029-0.086\end{array}$ & 0.002 \\
\hline FW & 0.86 & $\begin{array}{l}0.092 \\
0.062-0.122\end{array}$ & $<0.0001$ \\
\hline
\end{tabular}

Data for five zones are used in each city: 1) Urban Core (75\%>ISA $\geq 50 \%)$; 2) Urban1 (75\%>ISA $\geq 50 \%) ; 3)$ Urban2 (50\%>ISA $\geq 25 \%) ; 4)$ suburban (pixels located in a buffer zone of 0-5 km adjacent to and outside the 25\% ISA contour); and 5) Rural (non-urban pixels located in a $5 \mathrm{~km}$ wide ring located between 45 and $50 \mathrm{~km}$ away from the $25 \%$ ISA contour). LST data were collected between 2003 and 2005.

a Linear fit is not significant for desert cities. 

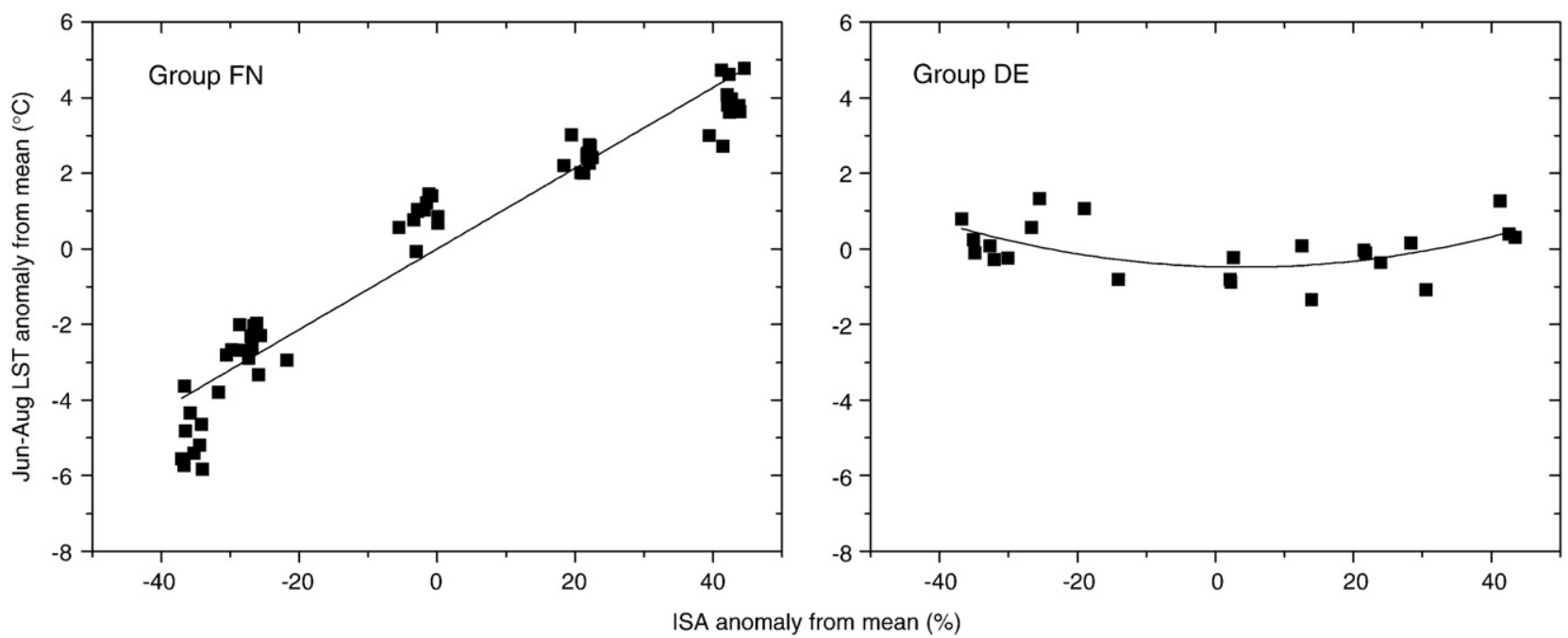

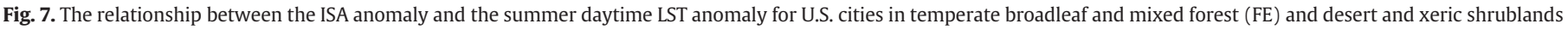

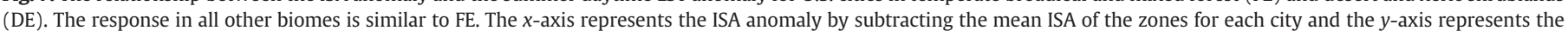
summer day LST anomaly by subtracting the mean LST for each city.

temperature at canopy level and contribute to the attenuation of the thermal contrast between the urban core and the surroundings.

For the desert groups, a polynomial relationship better describes the LST and ISA anomalies (Fig. 7b). The polynomial relationship explains about $26 \%$ of the LST variance in the five desert urban areas (group DE). Remarkably, however, if only Las Vegas and Phoenix are considered, more than $70 \%$ of the LST variance is explained by changes in ISA. This would indicate that there is considerable variation in the UHI response for desert cities possibly due to differences within the biome or the physical characteristics of the urban surfaces such as albedo and 3D structure not identifiable in the ISA data.

The heat island effect tends to be strongly dependent on the presence of vegetation within the different urban zones. For instance in Las Vegas and Phoenix, the coolest summer surface temperature is found in the third zone (Urban2) which has a fractional ISA between $50 \%$ and $25 \%$ and the highest NDVI. From this zone, LST increases in both directions (inward towards the urban hot core and outward towards the surrounding rural desert) by about $1{ }^{\circ} \mathrm{C}$. The surface temperature in the urban core is similar to that of the desert for an ISA anomaly of about $40 \%$.

\subsection{UHI and urban extent in temperate forest setting}

To examine the relationship between the total size of the urban area and the amplitude of the UHI we compare the total area of each urban polygon (summed areas of zones ISA $25 \%$ and greater) to the Urban Core-Rural temperature difference for 45 randomly selected cities within the NE biome. This sample set includes those cities listed in Table 2 under FE plus 34 additional cities located in that biome. Size in this case is the total contiguous area for an urban polygon defined by the $25 \%$ ISA threshold. We group the 45 cities based on size and analyze diurnal and seasonal UHI (Fig. 8). Our analysis indicates that for cities within this biome, the summer daytime UHI is strongly correlated to size. For instance, the averaged UHI is about $1.5^{\circ} \mathrm{C}$ for urban areas smaller than $10 \mathrm{~km}^{2}$, while it about $10{ }^{\circ} \mathrm{C}$ for urban areas larger than $1000 \mathrm{~km}^{2}$ (Fig. 8). This relationship holds true during the winter but with a much weaker UHI amplitude ranging from about $2.0{ }^{\circ} \mathrm{C}$ for urban areas smaller than $10 \mathrm{~km}^{2}$ to $3.5^{\circ} \mathrm{C}$ for urban areas larger than $1000 \mathrm{~km}^{2}$. A similar pattern is observed during the nighttime. The difference between the summer and winter UHI amplitude is indicative of the vegetation function in these temperate mixed forests. During summer when vegetation is physiologically active, the evaporative cooling is strong during the day and creates a pronounced UHI between impervious and vegetated zones. During winter, the contrast between the urban and rural zones is subdued when leaves are off and photosynthetic activity is down-regulated by cold temperatures. During summer nighttime, the UHI persists in all urban areas but with smaller amplitudes ranging from $1{ }^{\circ} \mathrm{C}$ for urban areas less than $1 \mathrm{~km}^{2}$ to $3.5^{\circ} \mathrm{C}$ for those urban areas larger than $1000 \mathrm{~km}^{2}$. During winter nights, the UHI effect is less than $1^{\circ} \mathrm{C}$ for the largest urban area.

Within the Northeastern temperate broadleaf mixed forest biome, the relationship between the UHI amplitude and total urban area is consistent among all of the cities (Fig. 9). The relationship between the UHI amplitude and size is log-linear and is given by:

$\Delta T_{\text {Urban-Rural }}=3.48 \log ($ Area $)+1.75$

and explains about $71 \%$ of the variance in UHI with a standard error of $\pm 1.6{ }^{\circ} \mathrm{C}$. This result is similar to the log-linear relationship between

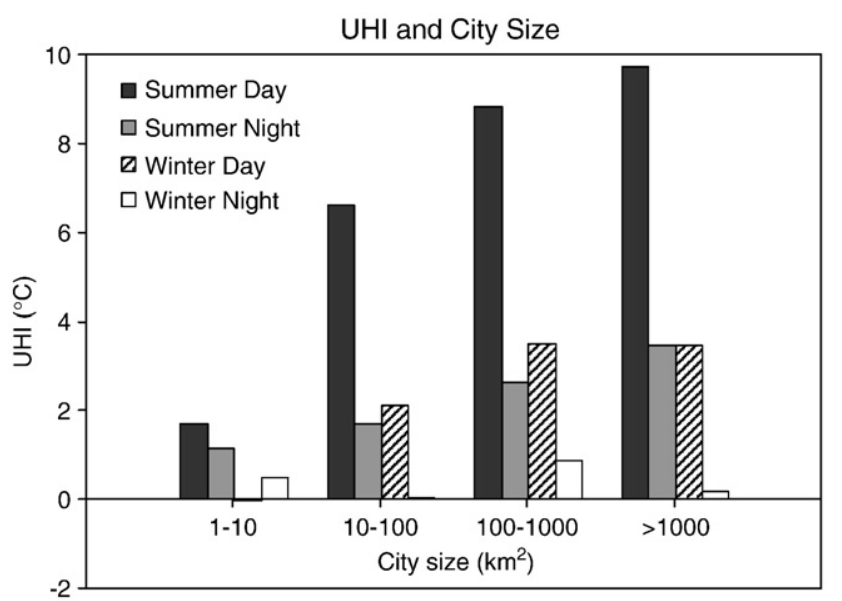

Fig. 8. Temperature difference between urban and the surrounding rural region for 45 sampled Northeast cities in four groups with different city area: 1-10 km²,10-100 km², $100-1000 \mathrm{~km}^{2}$, and $>1000 \mathrm{~km}^{2}$. Urban temperature is chosen from the most inner contour of each city and the rural temperature is the average of all the non-impervious pixels (ISA $<0.1 \%$ ) in the most outer contour $(15-20 \mathrm{~km}$ buffer ring). For each city, temperature differences for four different periods are examined: average summer (JunAug) daytime LST (1:30 PM), average summer nighttime LST (1:30 AM), average winter (Dec-Feb) daytime LST, and average winter nighttime LST. 
Total Area vs Urban Heat Island

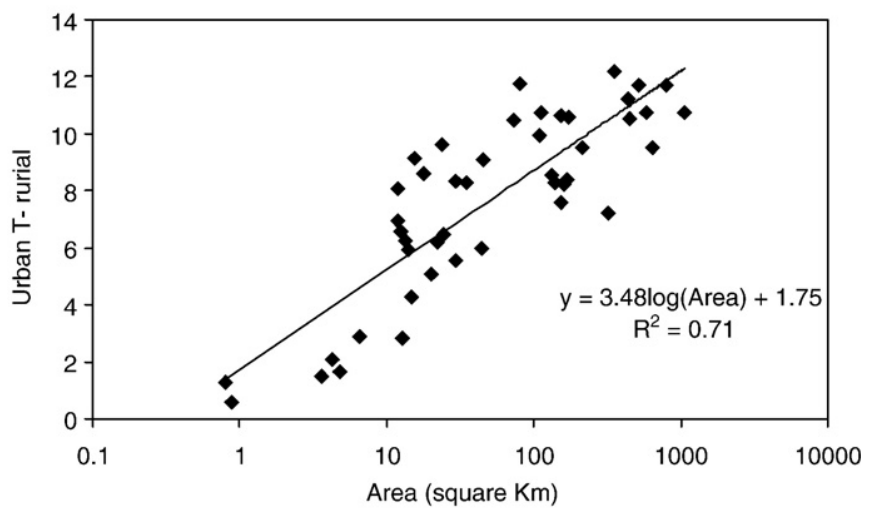

Fig. 9. The relationship between urban heat island and urban area size in Northeastern U.S. urban areas. The urban area size is defined as the total area surrounded by the $25 \%$ imperviousness contour of each city.

the UHI and the population size described in Oke $(1973,1976)$ and Landsberg (1981) only here we relate it directly to the size of the transformed surface (i.e., total area in a city having ISA $\geq 25 \%$ ).

\section{Summary}

In this study we combine remote sensing data from different platforms to assess the urban heat island amplitude and its relationship to urban spatial structure and size for a large number of cities across a variety of eco-climatic regions over the continental United States. We use a Landsat ETM + and IKONOS based dataset estimating the fractional area of impervious surfaces at $30 \mathrm{~m}$ and compare them to $1 \mathrm{~km}$ land surface temperature data from the MODIS instrument on the Aqua satellite for 38 of the most populous cities in the continental United States.

In general we find that the fraction ISA is a good predictor of LST for all cities in the continental United States in all biomes except deserts and xeric shrublands. The fraction of ISA explains about $70 \%$ of the total variance in LST for all cities combined with the highest correlations (90\%) in the Northeastern U.S. where urban areas are embedded in temperate broadleaf and mixed forests. More importantly, these correlations are consistent for small, medium and large urban areas. In most biomes, the LST is linearly proportional to the ISA fraction. The relationship between temperature and ISA for urban areas in deserts and xeric shrublands is more complicated requiring a second order polynomial with large variations in outcome if the analysis is conducted on fewer cities in the group. In desert type ecosystems suburban zones with moderate ISA fractions are cooler than the surrounding rural desert fringe and the urban core where ISA is usually above $75 \%$.

In terms of UHI's and biomes our results show that ecological context is a statistically significant modulator of the diurnal and seasonal UHI's in the continental United States. The largest (urban-rural) temperature differences for all biomes are found for summer midday and the greatest amplitudes are found for urban areas displacing forests $\left(6.5-9.0^{\circ} \mathrm{C}\right)$ followed by temperate grasslands $\left(6.3^{\circ} \mathrm{C}\right)$, and tropical grasslands and savannas $\left(5.0^{\circ} \mathrm{C}\right)$ respectively. Urbanization initiates a differential heating process between impervious surfaces, generally made of concrete and other heat absorbing materials, and the surrounding naturally vegetated landscapes. The contrast between urban cores and rural zones is driven by the surrounding land use type and is often accentuated during the time when the vegetation is physiologically active, especially in forested lands. In biomes with short vegetation the contrast is less. Similarly, the amplitude of the UHI is significantly diminished during the winter season when vegetation loses its leaves or is stressed by lower temperatures. Urban areas in deserts behave differently showing very little change relative to their non-urbanized surroundings. Our data show an overall heat sink pattern similar to that described by previous studies (e.g., Brazel et al., 2000; Pena, 2008); however, while our findings are consistent with theory, the temperature differences we find here are small (between 0.2 and $2.2{ }^{\circ} \mathrm{C}$ ) relative to the known accuracy of the MODIS LST product. In this paper we begin a characterization and inter-comparison of the UHI in the continental United States from a biomes perspective. This approach allows a broadscale appreciation of how ecological context influences UHI's. However, it does not reveal the complexities found in most urban environments where significant ecological variation is present at the finer scale. A logical next step to this characterization would be to use higher spatial resolution biome information capable of showing ecoregional variations within a city. Such an approach would permit city-scale investigations about the interplay between urban surfaces and their ecological settings and their impact on UHI and other related environmental issues.

Finally, this research highlights a significant positive relationship between the urban heat island magnitude, the size of the urban area, and ecological setting estimated entirely from remotely sensed observations. The use of ISA as an estimator of the extent and intensity of urbanization is more objective than population density based methods and can be consistently applied across large areas for inter-comparison of impacts on biophysical processes. Overall, our results suggest that remotely-sensed land surface temperature provides an adequate characterization of both the magnitude and spatial extent of the urban heat island and allow objective comparisons of urban heat island effects around urban areas of different sizes at continental scales without the significant bias encountered in conventional ground observations.

\section{References}

Arnold, C. L., Jr., \& Gibbons, C. J. (1996). Impervious surface coverage: The emergence of a key environmental indicator. Journal of the American Planning Association, 62(2), 243-258.

Bounoua, L., Safia, A., Masek, J., Peters-Lidard, C., \& Imhoff, M. L. (2009). Impact of urban growth on surface climate: A case study in Oran, Algeria. Journal of Applied Meteorology and Climatology, 48, 217-231.

Brazel, A., Selover, N., Vose, R., \& Heisler, G. (2000). The tale of two climates-Baltimore and Phoenix urban LTER sites. Climate Research, 15, 123-135.

Deichmann, U., Balk, D., and Yetman, G. (2001). Transforming population data for interdisciplinary usages: from census to grid. Documentation for GPW Version 2 available only at http://sedac.ciesin.columbia.edu/plue/gpw/GPWdocumentation. pdf

Farr, T. G., \& Kobrick, M. (2000). Shuttle radar topography mission produces a wealth of data. American Geophysical Union EOS, 81, 583-585.

Gallo, K. P., McNab, A. L., Karl, T. R., Brown, J. F., Hood, J. J., \& Tarpley, J. D. (1993). The use of NOAA AVHRR data for assessment of the Urban Heat Island effect. Journal of Applied Meteorology, 32(5), 899-908.

Gallo, K. P., \& Owen, T. W. (1999). Satellite-based adjustments for the urban heat island temperature bias. Journal of Applied Meteorology, 38, 806-813.

Grimmond, C. S. B., \& Oke, R. (2002). Turbulent heat fluxes in urban areas: observations and a Local-scale Urban Meteorological Parameterization Scheme (LUMPS). Journal of Applied Meteorology, 41, 792-810.

Hansen, J. E., Ruedy, R., Sato, M., Imhoff, M., Lawrence, W., Easterling, D., et al. (2001). A closer look at United States and global surface temperature change. Journal of Geophysical Research, 106, 23947-23963. doi:10.1029/2001JD000354

Homer, C., Huang, C., Yang, L., Wylie, B., \& Coan, M. (2004). Development of a 2001 national Land-Cover Database for the United States. Photogrammetric Engineering $\mathcal{E}$ Remote Sensing, 70(7), 829-840.

Huete, A. R., Justice, C., \& Liu, H. (1994). Development of vegetation and soil indices for MODIS-EOS. Remote Sensing Environment, 49, 224-234.

Huete, A. R., Liu, H. Q., Batchily, K., \& van Leeuwen, W. J. D. (1997). A comparison of vegetation indices over a global set of TM images for EOS-MODIS. Remote Sensing Environment, 59, 440-451.

Imhoff, M., Lawrence, W. T., Stutzer, D. C., \& Elvidge, C. D. (1997). Using nighttime DMSP/OLS images of city lights to estimate the impact of urban land use on soil resources in the US. Remote Sensing of Environment, 59, 105-117.

Imhoff, M. L., Tucker, C. J., Lawrence, W. T., \& Stutzer, D. C. (2000). The use of multisource satellite and geospatial data to study the effect of urbanization on primary productivity in the United States. IEEE Transactions on Geoscience and Remote Sensing, 38(6), 2549-2556.

Imhoff, M. L., Bounoua, L., DeFries, R., Lawrence, W. T., Stutzer, D., Tucker, C. J., et al. (2004). The consequences of urban land transformation on net primary productivity in the United States. Remote Sensing of Environment, 89, 434-443. 
Karl, T. R., Diza, H. F., \& Kukla, G. (1988). Urbanization: its detection and effect in the United States climate record. Journal of Climate, 1, 1099-1123.

Kukla, G., Gavin, J., \& Karl, T. R. (1986). Urban warming. Journal of Climate and Applied Meteorology, 25, 1265-1270.

Landsberg, E. H. (1981). The urban climate. International Geophysics Series, Vol. 28. (pp. 5) New York: Academic Press.

Lougeay, R., Brazel, A., \& Hubble, M. (1996). Monitoring intraurban temperature patterns and associated land cover in Phoenix, Arizona using Landsat thermal data. Geocarto International, 11, 79-90.

Lu, D., \& Weng, Q. (2006). Use of impervious surface in urban land-use classification. Remote Sensing of Environment, 102, 146-160.

Manley, G. (1958). On the frequency of snowfall in metropolitan England. Quarterly Journal of the Royal Meteorological Society, 84, 70-72.

Nichol, J. (1996). High-resolution surface temperature patterns related to urban morphology in a tropical city: a satellite-based study. Journal of Applied Meteorology, 35(1), 135-146.

Nichol, J., \& Wong, W. S. (2005). Modeling urban environmental quality in a tropica city. Landscape and Urban Planning, 73(1), 49-58.

Nizeyaimana, E., Petersen, G. W., Imhoff, M. L., Sinclair, H., Waltman, S., Reed-Margetan, D. S., et al. (2001). Assessing the impact of land conversion to urban use on soils with different productivity levels in the USA. Soil Science Society of America Journal, $65,391-402$.

Oke, T. R. (1973). City size and the urban heat island. Atmospheric Environment Pergamon Press, 7, 769-779.

Oke, T. R. (1976). The distinction between canopy and boundary layer urban heat islands. Atmosphere, 14, 268-277.

Olson, D. M., Dinerstein, E., Wikramanayake, E. D., Burgess, N. D., Powell, G. V. N., Underwood, E. C., et al. (2001). Terrestrial Ecoregions of the World: A New Map of Life on Earth. BioScience, 51(11), 933-938.

Owen, T. W., Carlson, T. N., \& Gillies, R. R. (1998). An assessment of satellite remotelysensed land cover parameters in quantitatively describing the climatic effect of urbanization. International Journal of Remote Sensing, 19(9), 1663-1681.

Quattrochi, D., \& Ridd, M. K. (1994). Measurement of thermal energy properties of common urban surfaces using the thermal infrared multispectral scanner. International Journal of Remote Sensing, 15(10), 1991-2022.

Pena, M. A (2008). Relationships between remotely sensed surface parameters associated with the urban heat sink formation in Santiago, Chile. Internationa Journal of Remote Sensing, 29(15), 4385-4404.

Reid, W. V. (1998). Biodiversity hotspots. Trends in Ecology and Evolution, 13, 275-280.

Ricketts, T., \& Imhoff, M. (2003). Biodiversity, urban areas, and agriculture locating priority ecoregions for conservation.Conservation Ecology, 8(2), 1 URL: http:// www.consecol.org/vol8/iss2/art1/

Rosenzweig, C., Solecki, W. D., Parshall, L., Chopping, M., Pope, G., \& Goldber, R. (2005) Characterizing the urban heat island in current and future climates in New Jersey. Environmental Hazards, 6, 51-62. doi:10.1016/j.hazards.2004.12.001
Roth, M., Oke, T. R., \& Emery, W. J. (1989). Satellite-derived urban heat islands from three coastal cities and the utilization of such data in urban climatology. International Journal of Remote Sensing, 10, 1699-1720.

Shepherd, J. M. (2005). A review of current investigations of urban-induced rainfall and recommendations for the future. Earth Interactions, 9(1), 1-27.

Shepherd, J. M. (2006). Evidence of urban-induced precipitation variability in arid climate regimes. Journal of Arid Environments, 67, 607-628.

Shepherd, J. M., \& Burian, S. J. (2003). Detection of urban-induced rainfall anomalies in major coastal city. Earth Interactions, 7(4), 1-17.

Sisk, T. D., Launer, A. E., Switky, K. R., \& Ehrlich, P. R. (1994). Identifying extinction threats. BioScience, 44, 592-604.

Streutker, D. R. (2002). A remote sensing study of urban heat island of Houston, Texas. International Journal of Remote Sensing, 23(13), 2595-2608.

Trenberth, K. E., Jones, P. D., Ambenje, P., Bojariu, R., Easterling, D., Klein Tank, A., et al. (2007). Observations: Surface and atmospheric climate change. Climate Change 2007: The Physical Science BasisIn S. Solomon, D. Qin, M. Manning, Z. Chen, M. Marquis, K. B. Averyt, M. Tignor, \& H. L. Miller (Eds.), Contribution of Working Group I to the Fourth Assessment Report of the Intergovernmental Panel on Climate Change Cambridge: Cambridge University Press.

UNFPA (2007). The state of world population 2007: Unleashing the potential of urban growth. United Nations Population Fund, United Nations Publications 1 pp.

Voogt, J. A., \& Oke, T. R. (2003). Thermal remote sensing of urban climates. Remote Sensing Environment, 86, 370-384.

Wan, Z., \& Dozier, J. (1996). A generalized split-window algorithm for retrieving landsurface temperature from space. IEEE Transactions on Geoscience and Remote Sensing, 34(4), 892-905.

Wan, Z., Zhang, Y., Zhang, Q., \& Li, Z. -L. (2004). Quality assessment and validation of the MODIS land surface temperature. International Journal of Remote Sensing, 25, $261-274$.

Wan, Z. (2008). New refinements and validation of the MODIS land-surface temperature/emissivity products. Remote Sensing of Environment, 112, 59-74.

Wang, W., Liang, S., \& Meyers, T. (2008). Validating MODIS land surface temperature products using long-term nighttime ground measurements. Remote Sensing of Environment, 112(3), 623-635.

Weng, Q., Dengsheng, L., \& Jacquelyn, S. (2004). Estimation of land surface temperature-vegetation abundance relationship for urban heat island studies. Remote Sensing of Environment, 89, 467-483.

Xian, G., \& Crane, M. (2005). Assessments of urban growth in the Tampa Bay watershed using remote sensing data. Remote Sensing of Environment, 97, 203-215.

Yang, L., Huang, C., Homer, C., Wylie, B., \& Coan, M. (2002). An approach for mapping large-area impervious surfaces: Synergistic use of Landsat 7 ETM + and high spatial resolution imagery. Canadian Journal of Remote Sensing, 29(2), 230-240.

Yuan, F. \& Bauer, M. E. (2007). Comparison of impervious surface area and normalized difference vegetation index as indicators of surface urban heat island effects in Landsat imagery. Remote Sensing of Environment, 106(3), 375-386. 